\title{
Detection of a Marine Birnavirus in Wild Molluscan Shellfish Species from Japan
}

\author{
Satoru Suzuki ${ }^{1,2 *}$ and Mayu Nojima ${ }^{1}$ \\ ${ }^{1}$ Department of Aquaculture, Kochi University, \\ Nankoku, Kochi 783-8502, Japan \\ ${ }^{2}$ Research Institute of Molecular Genetics, Kochi University, \\ Nankoku, Kochi 783-8502, Japan
}

(Received April 12, 1999)

\begin{abstract}
Thirteen wild molluscan shellfish species collected from 8 Prefectures in Japan were surveyed for the presence of marine birnavirus (MABV) by the polymerase chain reaction (PCR) technique and culture method. Approximately $60 \%$ of bivalves and $35 \%$ of gastropods tested had detectable MABV genome, although the prevalence of positive specimens varied among species. The PCR-positive shellfish were submitted to virus isolation. The isolation rate was low, suggesting that the MABV was in a state of persistent infection in these shellfish. Seventy four \% of the examined virus strains were different in a position of the nucleotide sequences of the PCR products from that of MABV strains obtained from fish.
\end{abstract}

Key words: marine birnavirus, shellfish, PCR, Mollusca, bivalve, gastropod

The marine birnavirus (MABV) has been associated with serious mortality in cultured fish (Sorimachi and Hara, 1985) and shellfish (Lo et al., 1988). Even though the virus does not appear to be strongly pathogenic, stressors such as spawning, heavy metals and change in temperature can increase host susceptibility and result in mortality (Chou et al., 1998; Suzuki et al., 1997a; 1998b). We have isolated MABV from Agemak (jack knife clam), Sinonovacula consticta (Suzuki et al., 1997a) and the Japanese pearl oyster, Pinctada fucata (Suzuki et al., 1998a), although the pathogenicity of the virus in the experimental infections appeared weak (Suzuki et al., 1997a; 1998b). The strains of MABV isolated from shellfish appear to be similar to strains from fish based on serological and genomic properties (Suzuki et al., 1997a; 1998a). This suggests that the host range of MABV may be very broad.

MABV has been reported to persistently infect marine fish (Isshiki et al., 1989). We have also found that several species of apparently normal wild fish from Shikoku Island, Japan, have detectable MABV (unpublished observation). Based on these observations, MABV is thought to be an opportunistic pathogen that persistently infects marine organisms, however, under stressful conditions the virus can be pathogenic to

* Corresponding author

E-mail: ssuzuki@cc.kochi-u.ac.jp cultured fish and shellfish. Thus it is important to know the natural reservoirs of MABV for the development of control strategies to minimize diseases caused by this virus.

Herein we report the results of a survey of MABV in wild shellfish species using the polymerase chain reaction (PCR) technique. The nucleotide sequences of the PCR products were examined and virus isolation was also performed.

\section{Materials and Methods}

\section{Samples}

Thirteen different species of molluscan shellfish were collected and sampled from 8 Prefectures in Japan (Fig. 1). Scallop in Hokkaido was obtained by dredge. Rock oyster, Japanese oyster, blue mussl, warty murex, bekkouzara, Japanese abalone and kubogai were collected in rocky reef in coastal areas. Japanese little neck was collected in sandy beaches. Common freshwater clam was collected in brackish water areas. Jack knife clam, species of ark shell and cockle were collected in muddy beaches. There were no aquaculture facilities around the sampling places. All samples were tested by a birnavirus specific PCR assay. Samples that were virus genome-positive by PCR were also tested using virus isolation techniques. 


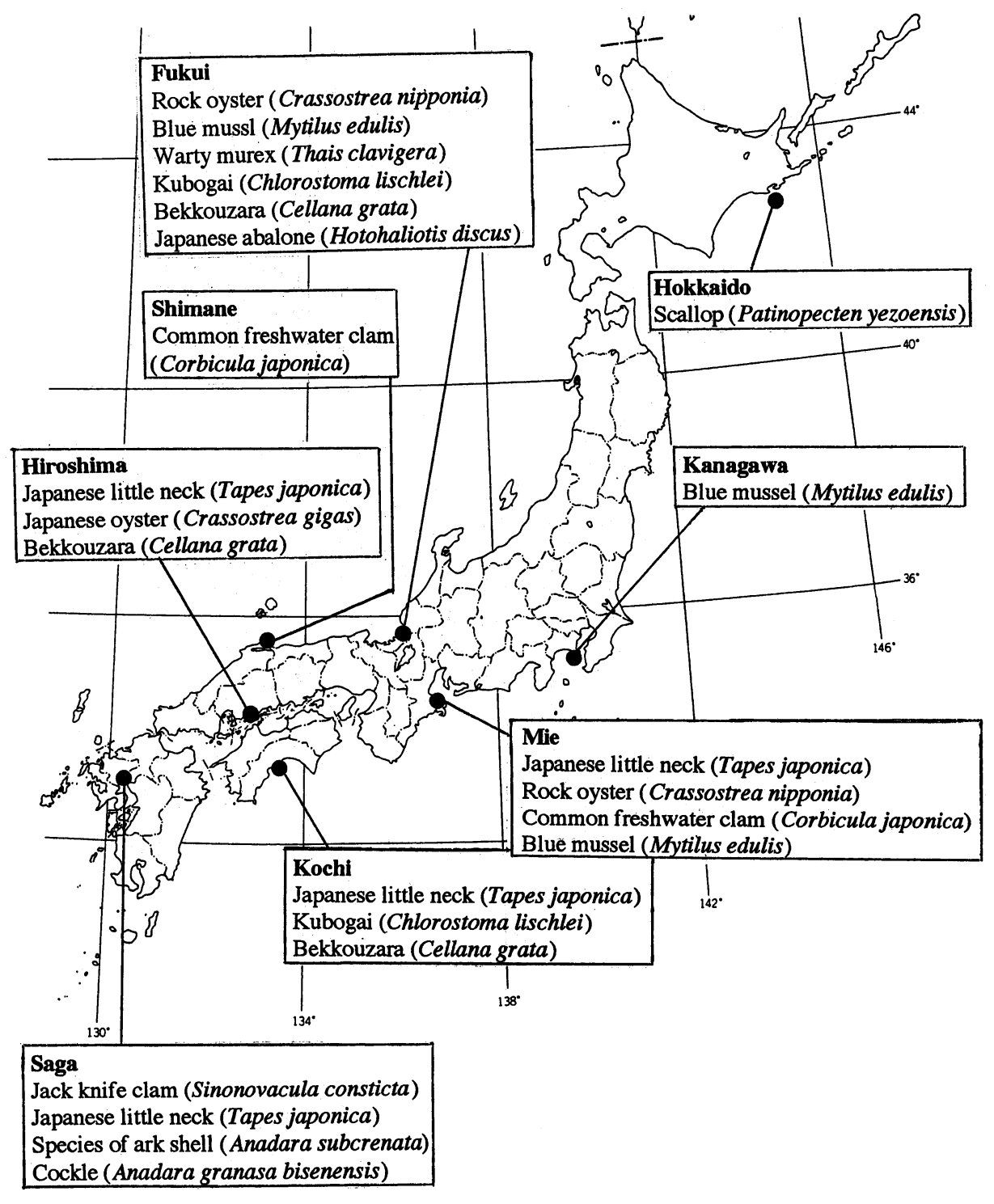

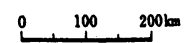

Fig. 1. Map of sampling areas and the species.

\section{PCR}

Birnavirus specific reverse transcription (RT)-PCR (Suzuki et al., 1997b) was used on all samples. Nested PCR was performed on samples that tested negative by RT-PCR. The PCR target region and the primers used for RT- and nested-PCR were reported in a previous paper (Suzuki et al., 1997b).

\section{Virus isolation}

All samples that tested positive by PCR were also tested using virus isolation techniques. Homogenates of the samples in Hanks' balanced salt solution were inoculated (25 and $10 \mu \mathrm{L} /$ well) onto the monolayers of RSBK-2 cells (Kusuda and Kawarasaki, 1993) cultured in 24-well tissue culture plate. If birnavirus specific cytopathic effect (CPE) was detected, new cells were reinoculated to substantiate the presence of a replicating agent.

\section{Nucleotide sequencing}

The nucleotide sequence of the PCR products was determined by the dideoxy termination procedure (Suzuki et al., 1998a). As references, PCR products of other isolated strains including Y-6 from yellowtail Seriora quinqueradiata (Kusuda et al., 1993), AGJ-90 from Japanese Agemaki, AGK-93 from Korean Agemaki (Suzuki et al., 1997a) and JPO-96 from Japanese pearl oyster (Suzuki et al., 1998b) were used for comparison.

\section{Results}

PCR survey

Most of the locations sampled had MABV-positive 
Table 1. PCR and virus isolation rates

\begin{tabular}{|c|c|c|c|c|c|}
\hline \multirow{2}{*}{ Prefecture } & \multirow{2}{*}{ Species name } & \multirow{2}{*}{$\begin{array}{l}\text { Code name } \\
\text { for sequencing }\end{array}$} & \multirow{2}{*}{ PCR positive ${ }^{* 1}$} & \multicolumn{2}{|c|}{ Virus isolation } \\
\hline & & & & 1st inoculation*2 & 2nd inoculation*3 \\
\hline \multirow[t]{2}{*}{ Hokkaido } & Scallop (Patinopecten yezoensis) gonad (A) & $\mathrm{HA}$ & $3 / 9$ & $2 / 3$ & $1 / 2$ \\
\hline & Scallop ligament (B) & $\mathrm{HB}$ & $8 / 9$ & $0 / 8$ & - \\
\hline \multirow[t]{6}{*}{ Fukui } & Rock oyster (Crassostrea nipponia) & $\mathrm{F} 1$ & $6 / 10$ & $4 / 6$ & $3 / 4$ \\
\hline & Blue mussl (Mytilus edulis) & $\mathrm{F} 2$ & $4 / 10$ & $1 / 4$ & $1 / 1$ \\
\hline & Warty murex (Thais clavigera) & F3 & $8 / 10$ & $0 / 8$ & - \\
\hline & Kubogai (Chlorostoma lischlei) & $\mathrm{F} 4$ & $1 / 9$ & $1 / 1$ & $0 / 1$ \\
\hline & Bekkouzara (Cellana grata) & F5 & $2 / 4$ & $1 / 2$ & $0 / 1$ \\
\hline & Japanese abalone (Hotohaliotis discus) & - & $0 / 4$ & - & - \\
\hline Kanagawa & Blue mussel & $\mathrm{Ka}$ & $5 / 7$ & $2 / 5$ & $0 / 2$ \\
\hline \multirow[t]{4}{*}{ Mie } & Japanese little neck (Tapes japonica) & M3 & $4 / 10$ & $2 / 4$ & $0 / 2$ \\
\hline & Rock oyster & M2 & $2 / 10$ & $2 / 2$ & $0 / 2$ \\
\hline & Common freshwater clam (Corbicula japonica) & M4 & $4 / 5$ & $2 / 4$ & $0 / 2$ \\
\hline & Blue mussel & M1 & $8 / 10$ & $4 / 8$ & $0 / 4$ \\
\hline \multirow[t]{3}{*}{ Hiroshima } & Japanese little neck & S1 & $4 / 5$ & $2 / 4$ & $0 / 2$ \\
\hline & Japanese oyster (Crassostrea gigas) & $\mathrm{S} 2$ & $6 / 10$ & $1 / 6$ & $0 / 1$ \\
\hline & Bekkouzara & S3 & $6 / 10$ & $1 / 6$ & $0 / 1$ \\
\hline Shimane & Common freshwater clam & $\mathrm{Si}$ & $3 / 4$ & $3 / 3$ & $0 / 3$ \\
\hline \multirow[t]{3}{*}{ Kochi } & Japanese little neck & $\mathrm{K} 1$ & $5 / 10$ & $2 / 5$ & $0 / 2$ \\
\hline & Kubogai & $\mathrm{K} 2$ & $1 / 4$ & $1 / 1$ & $0 / 1$ \\
\hline & Bekkouzara & K3 & $1 / 5$ & $1 / 1$ & $0 / 1$ \\
\hline \multirow[t]{4}{*}{ Saga } & Jack knife clam (Sinonovacula consticta) & A4 & $2 / 13$ & nd & - \\
\hline & Japanese little neck & A3 & $6 / 10$ & $2 / 6$ & $0 / 2$ \\
\hline & Species of ark shell (Anadara subcrenata) & $\mathrm{A} 2$ & $8 / 10$ & $2 / 8$ & $0 / 2$ \\
\hline & Cockle (Anadara granasa bisenensis) & $\mathrm{A} 1$ & $9 / 12$ & $2 / 9$ & $0 / 2$ \\
\hline
\end{tabular}

${ }^{* 1}$ positive number/sample number; ${ }^{* 2} \mathrm{CPE}$ like-change appearrance number/PCR positive number;

*3 real positive number of virus isolation/1st CPE like change-appearance number; nd, not done

specimens except for the abalone in Fukui prefecture (Table 1). There was variation in the PCR positive rate. For example, when the species were classified as either bivalvia or gastropoda, there was a significantly higher PCR-positive prevalence in the bivalvia species compared to species that belonged to gastropoda (Fig. 2). Significant difference of detection rate was not found for the sampling environments (data not shown).

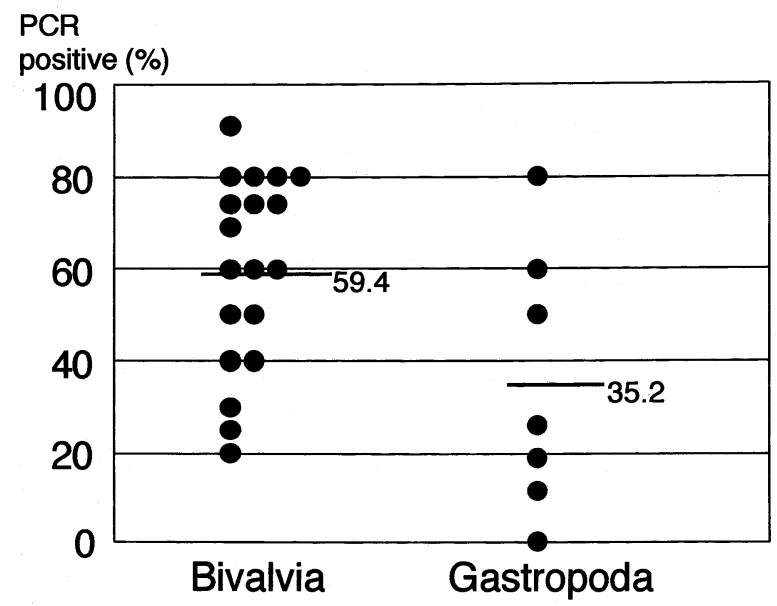

Fig. 2. Distribution of $P C R$ positive rate in bivalvia and gastropoda. Significant difference was at $P<0.01$.

\section{Virus isolation}

Virus isolation performed on PCR-positive samples exhibited MABV specific CPE like-change in many samples on primary inoculation (Table 1). However, secondary screening of these supernatants confirmed MABV in only 5 samples (Table 1).

\section{Nucleotide sequence}

Nineteen PCR products were randomly chosen for the sequencing. When the sequences were compared with the Y-6 strain, 74\% (14 out of 19) of the PCR products had a single base change at the 126th cytosine to thymine (Fig. 3). For shellfish strains AGJ-90 and AGK93, the sequence of the PCR products was different. However, the sequence from the Japanese pearl oyster JPO-96 strain was very similar to the majority of the PCR products.

\section{Discussion}

Farley et al. (1972) was the first to report a virus of shellfish where he found a herpes-like particle in the nuclei of the American oyster, Crassostrea virginica. Since that time, birnaviruses have been found in bivalves in Europe (Hill, 1976) and Taiwan (Lo et al., 1988). In recent years, we discovered that some bivalves in Japan and Korea are infected with MABV 


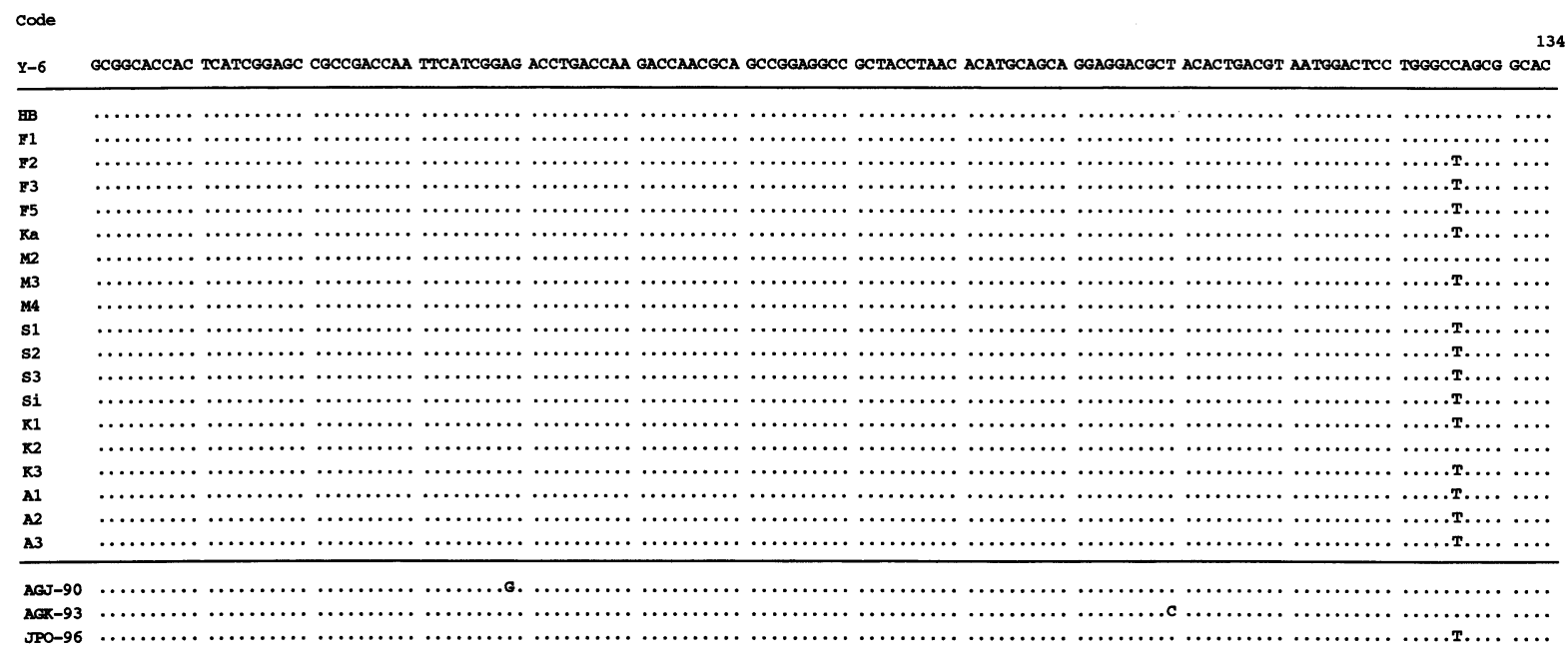

Fig. 3. Nucleotide sequences of the nested-PCR products except for the primer regions. MABV standard strain Y-6 (top) and the shellfish isolates from Agemaki (jack knife clam) and Japanese pearl oyster (bottom) were compared. Dot is the same base to $Y-6$.

(Suzuki et al., 1997a, 1998a). This study was undertaken to determine the distribution of MABV in different species of wild shellfish from Japan. The results indicated that most shellfish species possess MABV genome although the detection rate varied. This suggests that cultured shellfish, such as the pearl oyster, but also wild species function as carriers and/or reservoirs of MABV. In spite of the high PCR detection rate, the virus isolation rate was very low. This suggests that the virus is not actively replicating and may be in a persistent infection state. It can be thought that since the production of virus is small, the isolation rate and successful rate of the 2nd passage were low. When MABV was actively replicating, virus was isolated at a higher rate in Japanese pearl oyster (Suzuki et al., 1998a). Thus it is suggested that the infection of MABV in most wild shellfish is persistent infection but not latent infection. A comparison between bivalves and gastropodes revealed a higher PCR detection prevalence in bivalve species. This may be associated with the mechanism of feeding. Bivalves generally obtain their food from large volumes of water which may increase the chance of MABV infection. On the other hand, gastropodes tear off the surface of algae and do not intake seawater, which may give little chance of infection. A comparison among the collected places did not show significant differences, suggesting the distribution of MABV around Japan may not be dependent on the area.

It has been reported that blue mussl and oyster species are carriers of IPNV and have been detected in salmon aquaculture areas (Rivas et al., 1993). However, there are no reports on the genomic variation of viruses in carrier and/or reservoir organisms. The sequence analysis of PCR products reported in this study indicated that the genomes were very similar to the MABV Y-6 strain but not to IPNV. This suggests that marine shellfish located in different areas in Japan are infected with primarily MABV. In strain Y-6 the 126th base is a cytosine, however, $74 \%$ of the PCR products sequenced in this study showed that thymine was present in this position. This change was observed also in strain JPO-96 that originated from the Japanese pearl oyster. This suggests that this mutation may be shellfish specific. Since the AGJ-90 and AGK-93 strains have different mutations in the region, the significance of the 126th base mutation should be examined further.

The mechanism of disease manifestation in shellfish by MABV is still not understood. Recent reports suggest that heavy metal contamination may be a synergistic factor in clam mortality (Chou et al., 1998). Additionally, we have obtained the evidence that MABV could be isolated from Japanese pearl oyster in winter at which the virus replicates in liver tissue, although the virus could not be isolated in summer (Kitamura et al., submitted). This information suggests that MABV may persistently infect shellfish and some factors such as heavy metals and temperature change may activate virus pathogenicity and accelerate mortality. Molecular approaches must now be undertaken to reveal the host specific mutation that can influence pathogenicity.

\section{Acknowledgements}

The authors gratefully thank the following staffs who collected many shellfish species. Drs. M. Yoshimizu, Hokkaido University; K. Watanabe, Japan Sea-Farming Association; R. Kondo and T. Miyadai, Fukui Prefectural University; M. Nishimura, University of Tokyo; M. Kimura, Mie Aquaculture Centre; T. Nishizawa, R. Takano and L. Nonaka, Hiroshima University; Y. Furukawa and M. Yoshimoto, Ariake Fisheries Research 
and Development Centre.

We also thank to Dr. S. E. LaPatra for his review of this manuscript and to Dr. K. Kawai for his encouragement throughout this study. This study was supported in part by a Grant-in-Aid from MESSC, Japan, and a Grant from Japan Fisheries Resources Conservation Association.

\section{References}

Chou, H-Y., S-J. Chang, H-Y. Lee and Y-C. Chiou (1998): Preliminary evidence for the effect of heavy metal cations on the susceptibility of hard clam (Meretrix lusoria) to clam birnavirus infection. Fish Pathol., 33, 213-219.

Farley, C. A., W. G. Banfield, G. Kasnic Jr. and W. S. Foster (1971): Oyster herpes-type virus. Science, 178, 759-760.

Hill, B. J. (1976): Mollusc viruses: their occurrence, culture, and relationships. In "Proceedings of the first international colloquium on invertebrate pathology". pp. 25-29.

Isshiki, T., K. Kawai and R. Kusuda (1989): Incidence of yellowtail ascites virus (YAV) in wild yellowtail fingerlings. Nippon Suisan Gakkaishi, 55, 633-637.

Kusuda and Kawarasaki (1993): Establishment and characterization of a cell line derived from the kidney of red sea bream, Pagrus major. Suisanzoshoku, 41, 455-460.

Kusuda, R., Y. Nishi, N. Hosono and S. Suzuki (1993): Serological comparison of birnaviruses isolated from several spe- cies of marine fish in south west Japan. Fish Pathol., 28, 91-92.

Lo, C-F., Y-W. Hong, S-Y. Huang and C-H. Wang (1988): The characteristics of the virus isolated from the gill of clam, Meretrix lusoria. Fish Pathol., 23, 147-154.

Rivas, C., C. Cepeda, C. P. Dopazo, B. Novoa, M. Noya and J. L. Barja (1993): Marine environment as reservoir of birnaviruses from poikilothermic animals. Aquaculture, 115, 183-194.

Sorimachi, M. and T. Hara (1985): Characteristics and pathogenicity of a virus isolated from yellowtail fingerlings showing ascites. Fish Pathol., 19, 231-238.

Suzuki, S., N. Hosono and R. Kusuda (1997a): Detection of aquatic birnavirus gene from marine fish using a combination of reverse transcription- and nested PCR. J. Mar. Biotechnol., 5, 205-209.

Suzuki, S., T. Nakata, M. Kamakura, M. Yoshimoto, Y. Furukawa, Y. Yamashita and R. Kusuda (1997b): Isolation of birnavirus from Agemaki (jack knife clam) Sinonovacura consticta and survey of the virus using PCR technique. Fisheries Sci., 63, 563-566.

Suzuki, S., M. Kamakura and R. Kusuda (1998a): Isolation of birnavirus from Japanese pearl oyster Pinctada fucata. Fisheries Sci., 64, 342-343.

Suzuki, S., I. Utsunomiya and R. Kusuda (1998b): Experimental infection of marine birnavirus strain JPO-96 to Japanese pearl oyster Pinctada fucata. Bull. Mar. Sci. Fish. Kochi Univ., 18, 39-41. 